\title{
Antiangiogenic Therapy for Glioma
}

\author{
Valentina Cea, ${ }^{1}$ Carlo Sala, ${ }^{1,2}$ and Chiara Verpellii, \\ ${ }^{1}$ Department of Pharmacology, CNR Institute of Neuroscience, University of Milan, Via Vanvitelli 32, 20129 Milan, Italy \\ ${ }^{2}$ Neuromuscular Diseases and Neuroimmunology, Neurological Institute Foundation Carlo Besta, Via Celoria 11, 20133 Milan, Italy \\ Correspondence should be addressed to Carlo Sala, c.sala@in.cnr.it and Chiara Verpelli, c.verpelli@in.cnr.it
}

Received 9 January 2012; Revised 27 April 2012; Accepted 2 May 2012

Academic Editor: Laura Cerchia

Copyright () 2012 Valentina Cea et al. This is an open access article distributed under the Creative Commons Attribution License, which permits unrestricted use, distribution, and reproduction in any medium, provided the original work is properly cited.

\begin{abstract}
Currently, antiangiogenic agents are routinely used for the treatment of patients with glioma. However, despite advances in pharmacological and surgical therapy, glioma remains an incurable disease. Indeed, the formation of an abnormal tumor vasculature and the invasion of glioma cells along neuronal tracts are proposed to comprise the major factors that are attributed to the therapeutic resistance of these tumors. The development of curative therapeutic modalities for the treatment of glioma requires further investigation of the molecular mechanisms regulating angiogenesis and invasion. In this review, we discuss the molecular characteristics of angiogenesis and invasion in human malignant glioma, we present several available drugs that are used or can potentially be utilized for the inhibition of angiogenesis in glioma, and we focus our attention on the key mediators of the molecular mechanisms underlying the resistance of glioma to antiangiogenic therapy.
\end{abstract}

\section{Introduction}

Angiogenesis and tumor cell invasion play a critical role in glioma development and growth, even during the earliest phases [1]. Indeed, the formation of abnormal tumor vasculature and glioma cell invasion along white matter tracts are proposed to be the major causes of the therapeutic resistance of these tumors; thus, glioma remains a fatal disease despite advances in surgical and medical therapy.

Glioma tumors are an example of highly vascularized tumors, which induce angiogenesis by upregulating vascular endothelial growth factor (VEGF) and its downstream pathways. Indeed, several molecular abnormalities have been described in glioma that promote angiogenesis, such as mutations and/or upregulation of PI3K/Akt and the VEGF receptor (VEGFR) in the glioma endothelium [2]. Interestingly, each of these signaling pathways involves alterations that can be therapeutically targeted [3]. Evaluation of drugs that target these pathways requires novel preclinical and clinical experimental trial design to define the optimal drug dose and delivery times to avoid toxicity during the first months of treatment $[4,5]$. Furthermore, whether these agents can be used in combination with classical cytotoxic chemotherapy, what molecular markers can predict response, and whether they can be potentiated by such combinatorial treatments are important issues that remain to be explored.

In this paper, we first discuss the molecular characteristics of angiogenesis and invasion in human malignant glioma. Secondly, we discuss the commercially available drugs that are currently used or might be potentially utilized for the inhibition of angiogenesis in glioma. Thirdly, we focus our attention on the key mediators of the molecular mechanisms underlying the resistance that glioma exhibits to antiangiogenic therapy. Finally, we highlight the necessity for further investigation of the clinical utility of antiangiogenic therapies and the development of novel strategies for the treatment of glioma.

\section{Angiogenesis in Glioma}

Angiogenesis, the formation of new blood vessels, is a critical step during tumorigenesis and represents a pathological hallmark of cancer.

When a solid tumor, such as a brain tumor, grows larger than a critical size (1-2 $\mathrm{mm}$ in diameter), it must recruit new blood vessels to supply the required oxygen and nutrition levels necessary for its survival and proliferation. This process comprises the formation of new blood vessels 
from preexisting ones and is a crucial step in the progression of cancer from a small and localized neoplasm to a highly aggressive tumor. The major in vitro and in vivo models to study tumor angiogenesis are summarized and critically discussed in Table 1.

2.1. Mechanisms of Neoangiogenesis in Glioma. Angiogenesis requires three distinct steps: (1) blood vessel breakdown, (2) degradation of the vessel basement membrane and the surrounding extracellular matrix (ECM), and (3) migration of endothelial cells and the formation of new blood vessels.

Angiogenesis plays a crucial role in glioma development and growth [1]. Gliomas are highly vascularized tumors and neovascularization in and around the tumor are well characterized. Holash et al. reported also vascular cooption before the real agiogenesis in an experimental model of glioma [28]. The level of angiogenesis is correlated with the aggressiveness of gliomas and is often associated with prognosis. Glioblastomas (GBM) are the most lethal cancer and the most vascularized brain cancer, with the highest degree of vascular proliferation and endothelial cell hyperplasia [29]. Patients with high tumor microvascular densities exhibit shorter postoperative survival rates than patients with low microvascular densities [30, 31]. Perivascular migration, proliferation, and angiogenesis are closely associated and progress concurrently in gliomas.

2.2. Angiogenic Factors. Angiogenesis results from a balance between proangiogenic factors and antiangiogenic factors. During tumor progression, there is a shift towards angiogenic factors that stimulate uncontrolled and disorganized vascular growth. These molecular factors can be secreted by cancer, endothelial, stromal, and blood cells and by the extracellular matrix [32, 33].

Proangiogenic factors involve a variety of angiogenic factors including vascular endothelial growth factor (VEGF), acidic fibroblast growth factor, basic fibroblast growth factor, placental growth factor, angiopoietin-2, and interleukins, whereas antiangiogenic factors include angiostatin, endostatin, thrombospondin 1, and endothelial monocyteactivating polypeptide 2 [33, 34]. In addition, enzymes including serine proteinases and metalloproteinases degrade the extracellular matrix, which plays an important role in both the induction and the suppression of angiogenesis [35]. For example, Raithatha et al. [36] reported that MMP-9 might regulate angiogenic remodeling. Autocrine or paracrine factors of the glioma microenvironment and PDGF also contribute to angiogenesis in gliomas [37]. The endothelial cells that are stimulated by angiogenic factors then migrate and proliferate, resulting in neovascular formation [21]. This paracrine loop constitutes an extended foothold that allows tumor cells to migrate.

2.3. The VEGF/VEGFR Pathway. Accumulating evidence indicates that the VEGF and VEGFR signaling pathways play a major role in tumor angiogenesis in malignant glioma, similar to most other solid tumors.
VEGF-A is upregulated in glioblastoma and is produced by multiple cell types, including the tumor, stromal, and inflammatory cells [38]. The expression levels of VEGF are regulated by the following mechanisms: (1) low oxygen concentrations in growing gliomas induces upregulation of HIF that increases VEGF mRNA levels; (2) EGFR signaling stimulates VEGF gene expression via an HIF-independent mechanism; (3) FoxM1B transcription factor is upregulated in glioblastoma multiforme and stimulates VEGF expression independently of HIF [39]; (4) upregulation of the HuR protein that suppresses the posttranscriptional degradation of VEGF-A mRNA under hypoxia leads to a further increase in VEGF levels [40]; (5) brain-derived neurotrophin factor can enhance the expression of VEGF, increasing the levels of hypoxia-inducible factor-1 expression [41]; (6) integrinlinked kinase 1(ILK1) is an important regulator of tumor angiogenesis because it increases VEGF expression by stimulating HIF- $1 \alpha$ via AKT phosphorylation on $\operatorname{Ser}^{473}$ [42].

The two tyrosine kinase receptors, VEGFR-1 and VEGFR-2, are both highly expressed in gliomas [43]. They are activated by VEGF-A but are differentially linked to angiogenesis and glioma growth in vivo. VEGFR-2 is mainly expressed in vascular endothelial cells, where it directly transduces most of the mitotic signals that result in angiogenesis. In contrast, VEGFR-1 is expressed not only in vascular endothelial cells but also in monocyte/macrophage lineage cells. These macrophages can act as proangiogenic and protumorigenic cells, similar to the tumor-associated macrophages [44, 45].

VEGFR induces the activation of different signaling pathways including activation of Ras/Raf/mitogen-activated protein kinase $[46,47]$ and phospholipase $C-\gamma /$ protein kinase $C$ [47], which regulate endothelial cell proliferation and migration [48]. VEGF also enhances vascular permeability through the MAPK signaling cascade by rearranging cadherin/catenin complexes and perturbing the adherens junctions between endothelial cells $[49,50]$. Another important signaling cascade activated not only by VEGFR but also by other proangiogenic stimuli, including platelet-derived growth factor, neurotrophins, insulin-like growth factor, epidermal growth factor, and integrins, is the phosphatidylinositol-3 kinase/AKT pathway $[51,52]$, that is, fundamentally altered during brain tumor angiogenesis [53].

Notably, brain tumor blood vessels are tortuous, disorganized and highly permeable, resulting in irregular and inefficient blood flow [54-57] and vasogenic brain edema. This irregularity and inefficiency are strongly associated with the action of VEGF.

One of the insidious features of gliomas is their ability to metastasize and to establish numerous microtumors at a distance from the primary tumor. In all types of gliomas, the potential of single cells to invade normal brain tissue is closely related to angiogenesis.

The formation of abnormal tumor vasculature and glioma cell invasion along white matter tracts are believed to be the major factors responsible for the resistance of gliomas to treatment. Therefore, further investigation of the mechanisms underlying angiogenesis and invasion in glioblastoma is essential for the development of a curative therapy. 
TABLE 1: A critical summary of the major in vitro and in vivo models to study tumor angiogenesis.

\begin{tabular}{lll}
\hline Cellular models & Characteristics & References \\
\hline Human tumor cell lines & $\begin{array}{l}\text { There are a total of } 60 \text { cell lines representing nine distinct tumor types. However, this } \\
\text { model does not reflect the complexity of the real tumor environment. }\end{array}$ \\
\hline
\end{tabular}

Genes associated with cell survival, proliferation, differentiation, and resistance to therapy are differentially expressed in cells grown as multicellular spheroids versus $2 \mathrm{D}$ cultures.

The capacity for spheroid outgrowth in $3 \mathrm{D}$ matrices is an interesting parameter to study the migratory behavior of tumor spheroid cells; however, this parameter can only be used for rapidly migrating cells (e.g., glioblastoma spheroids).

Multicellular tumor Endothelial cell spheroids are increasingly used for evaluating the pro- and antispheroids angiogenic potential of drugs.

Cospheroids of HUVEC and human fibroblasts are used for angiogenesis studies.

Tumoral spheroids cocultured with endothelial cells potentiate tumor angiogenesis by upregulating proangiogenic factors that are absent in multicellular tumor spheroids alone or in monolayers.

Another advantage is the possibility to use tumor spheroids from biopsies. This is useful for the study and development of patient-specific therapies and for the presence of tumorinitiating cells and tumor progenitors stem cells in tumor spheroids.

Xenograft models Characteristics

The CAM tumor model could allow for a prescreening of drugs and subsequently reduce the number of animals used for in vivo experiments. This model is much faster than animal models. Histological analyses of the CAM tumors revealed a well-organized tumor

Chicken chorioallantoic membrane tumor assay tissue that strongly resembled clinical specimens of human tumors. The CAM model allows for the formation of tumors comparable to patient samples, with a degree of fidelity to human disease that is impossible to achieve with other nonanimal models; it combines the advantages of an in vivo environment with the simplicity of an in vitro experiment.

The duration of the follow-up period is limited due to the hatching of the chick 21 days after incubation.

Tumors were produced by Wechsler in Koestner'slaboratory by the i.v. administration of a single dose of ethyl-nitrosourea $(50 \mathrm{mg} / \mathrm{kg}$ b.w.) to a pregnant CD Fischer rat on the 20th day of gestation. The isolated clones retain individual characteristics, including

RG2 and F98 rat cell lines

Subcutaneously implanted human tumor xenografts

Orthotopic xenograft models

J3T-1 and J3T-2 orthotopic mice and rat models the differentiation status, despite repeated propagations in vitro, elevated mitotic index and an increased nuclear-cytoplasmic ratio consistent with glioma cells in culture. When injected, these tumors have been refractory to chemotherapy and radiotherapy and adaptive to immunotherapy and exhibit an infiltrative pattern of growth within the brain. These characteristics closely resemble those of human glioblastoma.

Tumors obtained from the direct implantation of the human cell lines or patient tumor biopsies are models that allow the monitoring of tumor growth. However, growth can be too slow; in xenografted models, the microenvironment and host immune responses are altered, and this may influence the tumor response.

This model mimics the morphology, growth characteristics of clinical disease and metastatic processes more efficiently. There are several studies that report differences in the therapeutic responses between subcutaneous and orthotopic models.

The traditional orthotopic models for brain tumors did not aggressively invade healthy brain tissues; for this reason, we do not have an ideal GBM animal model that incorporates all of the human GBM features.

Spontaneous canine glioblastoma approximates the human disease characteristics. However, it is not trivial to study a large number of spontaneous canine glioblastomas. The orthotopic xenograft implant of the two GBM cell lines, J3T-1 and J3T-2, into immunosuppressed mice and rats histologically recapitulated two invasive and angiogenic phenotypes: angiogenesis-dependent and angiogenesis-independent invasion observed in human glioblastoma.

Spontaneous/genetic models

Characteristics

References

The HGA murine models with Pten, Rb1, or Tp53 deletion are relevant to human disease, reflecting a spectrum of tumor histology and molecular features. Thus, molecular and other complex processes including specific contributions of the tissue microenvironment, such as tumor angiogenesis, can appropriately mimic human disease in these spontaneous
Tp53-deleted mice

tumor models. 
Table 1: Continued.

\begin{tabular}{|c|c|c|}
\hline $\begin{array}{l}\text { Spontaneous/genetic } \\
\text { models }\end{array}$ & Characteristics & Reference \\
\hline $\begin{array}{l}\text { VM-M3 spontaneous } \\
\text { tumors of the VM } \\
\text { mouse strain }\end{array}$ & $\begin{array}{l}\text { The inbred VM mouse strain is unique in exhibiting a relatively high incidence (1.5\%) of spontaneous } \\
\text { brain tumors. The VM-M3 brain tumor arose spontaneously in the forebrain of a VM mouse and } \\
\text { expresses properties of microglia/macrophages similar to that seen in several types of invasive cancers } \\
\text { of neural origin. Similar to high-grade human gliomas, the VM-M } 3 \text { tumor cells, highly invasive, can be } \\
\text { grown in the syngeneic VM mice with reproducible growth rates and have genetic similarities to human } \\
\text { GBM. In addition, the tumor cells are labeled with the firefly luciferase gene allowing for noninvasive } \\
\text { detection and quantitation of tumor growth. }\end{array}$ & {$[24]$} \\
\hline $\begin{array}{l}\text { Canine spontaneous } \\
\text { glioma }\end{array}$ & $\begin{array}{l}\text { GBM is the most common primary brain tumor in dogs and brachycephalic breeds such as Boston } \\
\text { terriers and Canine Boxers are genetically predisposed to develop these tumors. Spontaneous gliomas may } \\
\text { provide a valuable large animal model for the investigation of novel delivery and therapeutic strategies for } \\
\text { intracranial tumors. The presence of pseudopalisading necrosis and endothelial proliferation that closely } \\
\text { resemble those found in human GBMs suggests the presence of a hypoxic environment in canine GBM. } \\
\text { The large size of the canine brain compared to the rodent brain would be more useful for preclinical } \\
\text { assessment of doses, comprising more relevant volumes needed to implement novel therapies. However, } \\
\text { spontaneous GBM in dogs is not a tumor model that is as easily accessible as the rodent GBMs. These } \\
\text { models have variable penetrance, resulting in lack of synchrony in tumor development. The variability in } \\
\text { time to progression represents a limitation in its use for drug testing. }\end{array}$ & $\begin{array}{c}{[20,25} \\
26]\end{array}$ \\
\hline F98 rat glioma & $\begin{array}{l}\text { This tumor is produced by the administration of a single i.v. dose of ethylnitrosourea to a pregnant } \\
\text { rat. It has been classified as an anaplastic and undifferentiated glioma. It is refractory to chemotherapy } \\
\text { and radiotherapy. This model is effective for the evaluation of survival rate. However there are serious } \\
\text { limitations in directly applying data from rat tumor models to any clinical treatment for human brain } \\
\text { tumor. }\end{array}$ & {$[15,27]$} \\
\hline
\end{tabular}

\section{Antiangiogenic Therapy for Glioma}

Tumors require nutrients and oxygen in order to grow, and new blood vessels provide these requirements. GBM cells are characterized by their invasive abilities and striking angiogenic potential. The blood vessels formed by tumor cells are structurally and functionally abnormal: the blood vessels are leaky and dilated, the endothelial cells exhibit aberrant morphology, the pericytes are loosely attached or absent and the basement membrane is incomplete [14]. These abnormalities lead to an abnormal tumor microenvironment that is characterized by interstitial hypertension, hypoxia and acidosis. The abnormal vasculature represents a barrier to the delivery and efficacy of anticancer therapeutic agents. These observations suggest that if the structure and function of tumor vessels could be "corrected," then the tumor microenvironment might be normalized, ultimately improving the efficacy of cancer treatments.

As a key mediator of angiogenesis, VEGF and its receptors are targets for anticancer therapies [58], in addition to conventional therapies. Targeting the cells that support tumor growth, rather than the actual tumor cells, represents a relatively new approach to cancer therapy. This approach is particularly promising because these support cells are genetically stable and therefore less likely to develop mutations that will allow them to develop drug resistance in a rapid manner.

A significant challenge for antiangiogenic therapy is to design combination protocols that can counteract the diverse angiogenic stimuli produced by the tumor and its microenvironment.

VEGF signaling inhibitors have been shown to significantly suppress or delay tumor growth in several animal models [59] and in clinical trials. The humanized mono- clonal anti-VEGF antibody bevacizumab is the first VEGFtargeting drug approved for use in patients with metastatic colorectal cancer [60], metastatic breast cancer, lung cancer, renal cell carcinoma, and glioblastoma multiforme [61].

VEGF expression is regulated by intrinsic and extrinsic factors. Hypoxia and hypoglycemia are major stimulators of VEGF expression [62]. Factors that can potentiate VEGF production and stimulate angiogenesis include tumor necrosis factor and transforming growth factor.

Several approaches have been used to eliminate the hypoxic cells within tumors [63].

3.1. Antiangiogenic Strategies. Angiogenesis inhibitors have been divided into two classes: direct and indirect [64]. Direct angiogenesis inhibitors, such as endostatin, target the microvascular ECs, preventing their response to various proangiogenic stimuli and thereby enhancing the effects of chemotherapy.

In contrast, indirect angiogenesis inhibitors interfere with the proangiogenic communication between the tumor cells and the endothelial cell compartments. Antiangiogenic therapies act predominantly by blocking the binding of VEGF to its receptor and comprise neutralizing antibodies against the ligand or the receptor, soluble receptors, or small molecule inhibitors directed against the tyrosine kinase activity of the VEGF receptors.

Due to the potential of tumor "escape" when specific, indirect antiangiogenic agents (e.g., anti-VEGF) are delivered individually, appropriate combination protocols employing these agents are required for maximal benefit [65]. Abdollahi and coworkers show that the treatment of tumor xenografts with a combination of endostatin and 
with VEGF blockers results in an enhanced therapeutic effect, which may be attributed to the endostatin-mediated downregulation of many regulators of proangiogenic pathways and suppression of alternative angiogenic mechanisms that might be upregulated by VEGF blockade [66].

Here, we focus on several molecules that interfere with the VEGF/VEGFR signaling pathway, which have been evaluated in clinical trials for solid tumors. In Table 2, we summarize the available treatments and the relative clinical phases and results.

3.2. Indirect Antiangiogenic Drugs. As mentioned previously, Bevacizumab (Avastin) is a humanized neutralizing monoclonal antibody that blocks the binding of human VEGF to its receptors. A significant tumor response was observed in response to Bevacizumab treatment: the 6month progression-free survival was $32 \%$ in GBM patients [84]. However, glioblastoma appears to adapt rapidly to antiVEGF therapy, resulting in rapid tumor progression without improvement in overall survival $[85,86]$.

In recent study demonstrated that anti-VEGF therapies can significantly reduce the vascular supply, as demonstrated by a decrease in intratumoral blood flow and a strong reduction of large- and medium-size blood vessels, however these events were also shown to be accompanied by a strong increase in infiltrating tumor cells in adjacent brain parenchyma [87]. Finally, a preclinical study [88] and a clinical trial [89] suggest that high doses of bevacizumab could directly enhance the invasiveness of human glioblastoma cell lines and that dosages lower than those currently used might improve patient outcome.

In the endothelial cells of normal animals, VEGF-A treatment results in the upregulation of both integrins $\alpha 1 \beta 1$ and $\alpha 2 \beta 1$. The functional blocking of these integrins impairs angiogenesis in vitro and reduces VEGF-A-induced angiogenesis and tumor growth in vivo [90, 91]. $\alpha \mathrm{v} \beta 3$ integrins are highly expressed by proliferating and activated vascular endothelial cells. Therefore, they are a major contributor to the formation of vasculature by supporting the migration and survival of endothelial cells [92]. The blockade of $\alpha \mathrm{v} \beta 3$ integrins inhibits tumor angiogenesis as well as blood vessel formation in in vivo models $[93,94]$. Consequently, $\alpha \mathrm{v} \beta 3$ might represent a potential target in antiangiogenic therapy. Antagonizing integrins has generally included the targeting of the receptor binding sites or other nearby sites, although new alternative approaches target downstream signaling proteins.

Cilengitide is a cyclic RGD-peptide inhibitor of $\alpha \mathrm{v} \beta 3$ and $\alpha \mathrm{v} \beta 5$ integrins. Blocking $\alpha \mathrm{v} \beta 3$ integrin inhibits blood vessel formation in vivo [95]. In a phase II trial, cilengitide was associated with a median survival of 10 months in recurrent glioma patients [96]. Cilengitide is currently in clinical phase III studies for the treatment of glioblastomas and is in phase II studies for the treatment of several other tumor types, including breast cancer, squamous cell cancer, nonsmall cell lung cancer, and melanoma [97, 98].

Other drugs targeting integrins include the following agents.
Abergrin is a humanized antibody against $\alpha \mathrm{v} \beta 3$ integrins. It blocks integrin binding to vitronectin and fibrinogen, preventing cell adhesion, migration, proliferation, and integrinmediated cell signaling [99].

Volociximab is a chimeric human-mouse monoclonal antibody that binds to $\alpha 5 \beta 1$ integrins. It induces cell death and prevents capillary tube formation in vitro. In vivo, volociximab exhibits antitumor and antiangiogenic effects [100].

Increased matrix metalloproteinase (MMP) levels are associated with glioma invasion and angiogenesis. Marimastat reduces MMP levels in patients with gliomas [73]. Phase II clinical trials evaluating the administration of marimastat in combination with temozolomide demonstrated promising results (the progression-free survival after six months was $39 \%$ ), although further investigation is needed for the associated therapy-induced joint pain [101].

Sorafenib (Nexavar) is a multi-kinase inhibitor of VEGFR2-3, PDGFR, Raf kinase, and c-Kit. It is currently approved for the treatment of advanced HCC and renal cell carcinoma. Phase II trials evaluating the efficacy of sorafenib in patients with malignant glioma are currently ongoing [102]. Hypertension is a specific side effect of sorafenib and of most antiangiogenic agents due to the decreased production of nitric oxide and prostacyclins in vascular endothelial cells [103].

Cediranib (Recentin) is a potent inhibitor of both VEGFR-1 and VEGFR-2. It also exhibits activity against ckit, PDGFR-beta and FLT4. It is well tolerated, and an inverse correlation was found between cediranib dose- and timedependent treatment and soluble VEGFR-2 [104].

Sunitinib (Sutent) is a multi-kinase inhibitor of VEGFR 1-3, RET and PDGFR, approved for treatment of RCC, imatinib-resistant gastrointestinal stromal tumors (GIST) and pancreatic neuroendocrine tumors (pNET) [105-107]. A recent preclinical study [108] shows that after starting sunitinib treatment, there is a period when tumor oxygenation is higher in treated compared to untreated mice. The improved oxygenation suggests that the residual blood vessels had improved function in terms of delivering oxygen and nutrients. A synergistic delay in tumor growth was observed when radiation was applied during the enhanced tumor oxygenation after 4 days of sunitinib administration.

Imatinib is a kinase inhibitor of PDGFR, c-kit, and bcrabl. Administration of imatinib at low concentrations can act as a cytostatic agent, whereas at high concentrations, it predominantly behaves as a cytotoxic agent [109]. Imatinib monotherapy has failed due to the limited penetration of the drug across the $\mathrm{BBB}$, and for that reason, the inhibition of PDGFR alone is insufficient to prevent the growth of malignant gliomas [110].

Antiangiogenic therapies are integrated into the treatment strategies for many different tumor types. However, not all patients respond to therapy; only a few benefit with progression-free survival. In most tumors, antiangiogenic treatment is combined with chemotherapy. Furthermore, a major problem of this therapy is the development of resistance. Extensive evidence indicates that antiangiogenic therapy might actually enhance tumor progression by 
TABLE 2: Summary of the available treatments and the relative clinical phase and results.

\begin{tabular}{lcc}
\hline Drug & Target & Clinical phase \\
\hline Endostatin (Endostar) & $\begin{array}{c}\text { Interfere with the proangiogenic } \\
\text { action of growth factors }\end{array}$ & Phase III 2005 \\
\hline Bevacizumab (Avastin) & Monoclonal antibody anti-VEGF & Approved in 2004 \\
& & \\
& & \\
Cilengitide & Selective inhibitor of $\alpha \mathrm{v}$ integrins & $\begin{array}{c}\text { Ourphean drug by } \\
\text { agency in 2008 }\end{array}$
\end{tabular}

Results rate, median time to tumor progression, and clinical benefit rate in combination with chemotherapy [67].

In May 2009, the FDA approved Avastin as a single agent for the treatment of recurrent GBM based on the demonstration of objective response rates in two single-arm trials: AVF3708g and NCI 06-C0064E.

Phase II trial in conjunction with chemotherapy and radiation: EMD 121974 in 2010 phase II trial in recurrent glioblastomas. The efficacy of the cilengitide alone is modest, but it is adequately delivered to the tumor [68]. In a phase II study, the addition of cilengitide to standard chemoradiotherapy demonstrated promising activity in GBM [69].

\begin{tabular}{|c|c|c|c|}
\hline Etaracizumab (Abegrin) & $\begin{array}{l}\text { Humanized monoclonal } \\
\text { antibody direct against the } \\
\text { human } \alpha \mathrm{v} \beta 3 \text { integrin }\end{array}$ & Phase II/phase I & $\begin{array}{l}\text { Well tolerated with no evidence of immunogenic- } \\
\text { ity [70]. Does not improve the effect of dacar- } \\
\text { bazine in a phase II trial of metastatic melanoma } \\
{[71] \text {. }}\end{array}$ \\
\hline Volociximab & $\begin{array}{l}\text { Chimeric monoclonal antibody } \\
\text { that binds to and inhibits } \alpha \mathrm{v} \beta 1 \\
\text { integrin }\end{array}$ & Phase II & $\begin{array}{l}\text { Despite insufficient clinical activity in the refrac- } \\
\text { tory patient population to continue the study, } \\
\text { weekly volociximab was well tolerated. A bet- } \\
\text { ter understanding of the mechanism of action } \\
\text { of volociximab will inform future development } \\
\text { efforts [72]. }\end{array}$ \\
\hline Marimastat & $\begin{array}{c}\text { Broad-spectrum matrix } \\
\text { metalloproteinase inhibitor }\end{array}$ & Phase III & $\begin{array}{l}\text { Treatment with marimastat in SCLC and GBM } \\
\text { patients does not improve survival }[73,74] .\end{array}$ \\
\hline Sorafenib & $\begin{array}{c}\text { Small molecular inhibitor of } \\
\text { several tyrosine protein kinases } \\
\text { (VEGFR and PDGFR) and Raf } \\
\text { kinases }\end{array}$ & $\begin{array}{l}\text { Approved in } 2007 \text { for } \\
\text { liver and kidney } \\
\text { cancer }\end{array}$ & $\begin{array}{l}\text { Phase I and II trials for brain tumors. Sorafenib } \\
\text { can be safely administered }[75,76] \text {. }\end{array}$ \\
\hline Cediranib & Potent inhibitor of VEGFR & Phase I, Phase II & $\begin{array}{l}\text { Modest single-agent activity }[77,78] \text {. Cediranib } \\
\text { monotherapy yielded encouraging responses in } \\
\text { recurrent glioblastoma in a phase II study [79]. }\end{array}$ \\
\hline Sunitinib & $\begin{array}{l}\text { Multi-target receptor tyrosine } \\
\text { kinase inhibitor }\end{array}$ & $\begin{array}{l}\text { Approved for renal } \\
\text { cell carcinoma and } \\
\text { for imatinib-resistant } \\
\text { gastrointestinal } \\
\text { stromal tumor }\end{array}$ & $\begin{array}{l}\text { Single-agent sunitinib exhibited insufficient activ- } \\
\text { ity in patients with recurrent glioblastoma in a } \\
\text { phase II study [80]. }\end{array}$ \\
\hline Imatinib & $\begin{array}{l}\text { Specific inhibitor of receptor } \\
\text { tyrosine kinase }\end{array}$ & $\begin{array}{l}\text { Approved in } 2011 \text { for } \\
\text { ten different cancer } \\
\text { types }\end{array}$ & $\begin{array}{l}\text { In brain tumors, it did not show clinically mean- } \\
\text { ingful antitumor activity in phase II and phase III } \\
\text { trials }[81-83] \text {. }\end{array}$ \\
\hline
\end{tabular}

promoting an invasive phenotype that allows for tumor cells to escape angiogenic inhibition.

The identification of predictive biological markers of objective response will be critical for the assessment of the response rates correlated with overall survival and of the development of resistance to antiangiogenic drugs. These markers will provide important indices to aid in the improvement of therapeutic efficacy or in the development of alternative antiangiogenic therapies in the event of treatment failure.

\section{Molecular Mechanisms of Resistance to Antiangiogenic Therapy in Glioma}

VEGF is ubiquitously expressed in almost all tumors. Tumor cells have been demonstrated to secrete VEGF, which leads to increased angiogenesis [111, 112].

Although antiangiogenic treatment yields survival benefits for patients with many different types of aggressive tumors, VEGF pathway inhibitors are nonetheless failing to produce enduring clinical responses in most patients 
$[113,114]$. Here, we discuss the different ways that tumors can circumvent antiangiogenic therapy.

4.1. Alternative Pathway Activation by Tumoral Cells. One way that tumor cells bypass antiangiogenic therapy is via the activation or upregulation of alternative proangiogenic pathways. In preclinical models and in clinical trials, overexpression of fibroblast growth factor 1 and 2, ephrin, and angiopoietin was found in tumors that were treated with inhibitors of VEGF signaling [115].

Pericytes play an important role in the pathology of aberrant tumor vasculature. The vessels within tumors that survive antiangiogenic therapy are tightly covered with pericytes, which are recruited by vascular endothelial cells to provide VEGF, the most important survival signal for endothelial cells [116]. Important features of hypoxic remodeling include the loss of small vessels and extensive proliferation of vascular mural cells (MCS) in the surviving vasculature. PDGF-B appears to play a significant role in promoting the integrity of vascular networks during conditions of environmental stress. Recruited MCs are key contributors to the maintenance of tumor neovasculature. PDGF-B signaling via the PDGF receptor- $\beta$ (PDGFR- $\beta$ ) plays a critical role in MC recruitment [117]. Similar to VEGF, PDGF-B expression in ECs is critically regulated by oxygen tension, and PDGF-B overexpression is associated with abnormal proliferation of MCs [118]. Members of the ephrin family have been shown to play important roles in regulating the assembly of vascular cells.

However, increased PDGF-B expression has only been found in recurrent xenografts. PDGFR- $\beta$ was also found in the large vessels of the recurrent tumors. Prolonged antiangiogenic therapy significantly alters the expression of angiogenic factors implicated in vascular MC recruitment, causing extensive morphological changes in vessels, including significant increases in diameter and active proliferation of vascular mural cells [119].

Cancer cells can also adapt to the disruption of vessels by extravagating into normal tissues [120].

An alternative mechanism of escaping from VEGF blockade might be attributed to the local contribution of VEGF by the host stroma, which is sufficient to maintain persistent vessels and to sustain tumor growth. When host-derived VEGF is blocked, tumors exhibit extensive necrosis [121]. Breast cancer studies have revealed that mammary stromal fibroblasts might produce factors that influence the growth and malignant progression of a tumor via paracrine effects on the tumor-associated endothelium [122].

4.2. The Tumor Recruits Different Types of Cells. Tumor hypoxia caused by the loss of functional vasculature after conventional therapy (e.g., irradiation) results in the upregulation of VEGF to stimulate vascular proliferation and is the stimulus for the influx of BMDCs (bone-marrowderived endothelial cells). The two principal ways in which a tumor can expand its vasculature as it grows is either by angiogenesis, which involves the sprouting of endothelial cells from nearby normal vessels, or by vasculogenesis, which occurs by the recruitment of circulating endothelial and other cells into the tumor. Both the pharmacological or genetic inhibition of HIF- $1 \alpha$ attenuates BMDC recruitment and inhibits tumor recurrence. Such BMDC accumulation is composed largely of CD11b+ monocytes. These cells are highly proangiogenic, suggesting that they are attractive targets for enhancing the response of tumors to irradiation $[123,124]$. In addition, CD11b+Gr-1+ cells (also defined as myeloid-derived suppressor cells, MDSC) have been found to be frequently increased in tumors and to mediate their resistance to anti-VEGF treatments by producing several angiogenic factors including G-CSF and Bv8 [125].

Other cells are important for tumor growth and angiogenesis. For instance, there is an inverse relationship between macrophage density and vascular density [126]. Hypoxia upregulates the production of proangiogenic growth factors and cytokines by tumor-associated macrophages (TAM) [127]. Macrophage infiltration was demonstrated to be a prerequisite step for the angiogenic switch, which correlates with the transition to a malignant tumor phenotype [128]. TAMs secrete a number of mitogenic cytokines and growth factors, which are involved in a range of paracrine loops that promote tumor cell proliferation and growth. A number of studies have shown that TAM infiltration correlates with increased cell proliferation growth of many tumors [129]. The indirect role of TAMs in angiogenesis is also essential for tumor growth, as they provide oxygen and nutrients.

Microglia and macrophages can be recruited either by resident brain microglia or by activated perivascular macrophages. Microglia are recruited to the glioma, where they can produce cytokines to benefit glioma cell proliferation and migration. The cytokines produced include MCP-1 (monocyte chemoattractant protein-1) [130], GCSF (Granulocyte colony stimulating factor) [131], and several growth factors such as EGF, VEGF, HGF, and SCF $[132,133]$. HGF, and its receptor are expressed in both microglia and glioma and stimulates angiogenesis, metastasis and proliferation $[134,135]$. Upregulation of TGF $\beta$ might be involved in promoting tumor proliferation and invasion, whereas TNF $\alpha$ is mainly produced by microglia because it has been found to be overexpressed in human glioma but not in isolated glioma cell lines [136].

Initially, infiltration of microglia has been proposed to defend the brain parenchyma against tumor cells [137]. However, microglia can interact with the tumor environment and, when activated by the glioma, secrete factors including MMPs that degrade the ECM. Thus, utilizing this strategy, glioma cells can invade and expand into the brain parenchyma [138].

Some characteristics of macrophages/microglia are also exhibited by tumor cells. The phagocytic activities observed in human GBM are properties of malignant macrophaes/ microglia [139]. Subpopulations of neoplastic GBM cells exhibit the phagocytic behavior of macrophages/microglia. Notably, GBM tumors contain cells that are positive for both the phagocytic macrophage/microglia marker CD68 and tumor markers such as hTERT. As microglia are the resident macrophages of the brain, subpopulations of the malignant GBM cells could also arise from microglia/macrophages [140]. 
Myeloid cells have been observed to fuse with tumor cells, producing daughter cells endowed with the invasive properties of myeloid cells and the unlimited proliferative potential of tumor cells (reviewed in [141]). More recently, Pawelek and Chakraborty. demonstrated that the fusion between nonmetastatic cells and macrophages can result in cells with the ability to invade and metastasize [142]. Macrophage/microglial antigens are expressed on neoplastic cells within GBM [143]. It is possible that macrophages fuse with tumor cells during attempts to engulf the cells but that the resulting fusion produces more aggressive and invasive tumor cells [144].

VEGF blockade might be more effective if combined with therapies that also damage endothelial cells. Because endothelial cells proliferate at a slower rate than tumor cells, after the administration of a low-dose cytotoxic therapy, normal endothelial cells might be able to survive during the recovery period [145].

Anti-VEGF treatment suppresses the vasculature but not the coopted vessels [146]. Electron microscopic analysis of capillary formation has found that the complex vascular structures within tumors are composed essentially of progenitor endothelial cells. Cells with ultrastructural features of endothelial progenitors are recruited to the tumor periphery prior to vessel formation. Endothelial progenitors are migratory endothelial cells with characteristic ultrastructural features and the capacity to circulate, proliferate and differentiate into mature endothelial cells [147].

Vascular endothelial cells might also represent a target for cytotoxic therapy, as they might be capable of resuming growth during the recovery period after the cytotoxic treatment. However, Browder et al. hypothesized that endothelial cell recovery occurring during this treatmentfree period might support the regrowth of tumor cells. This could increase the risk of the emergence of drug-resistant tumor cells [145]. Considering that chemotherapeutic agents themselves can elicit antiangiogenic effects, dosing schedules must be carefully designed to induce maximal apoptosis of the endothelial cells. Some chemotherapeutic agents, in particular, exhibit maximal benefit when administered at a low-dose for long treatment periods (metronomic therapy). The same group has conducted a clinical trial in which children with recurrent or progressive cancers were treated with low-dose chemotherapy in combination with antiangiogenic therapy. Forty percent of patients exhibited prolonged or persistent disease-free status for all of the six months of therapy [148].

Recent studies suggest that tumor cells can also be involved in tumor angiogenesis, as neoplastic lesions have been found to contain tumor-derived endothelial cells (TDECs). These cells originate from the tumor-initiating cells but not from EC progenitor cells. Through the activation of HIF- $1 \alpha$, hypoxia plays an important role in endothelial differentiation. This switch is independent of VEGF or FGF. In this model, the VEGF inhibitor treatment elicited no effects on tumor growth [149].

Tumors can adapt to treatment with angiogenesis inhibitors by activating alternative angiogenesis-promoting mechanisms to sustain tumor growth [150].
In clinical trials evaluating bevacizumab, sorafenib and sunitinib, a minority of individuals failed to show even transitory clinical benefit [151]. In these cases, the tumors exhibited preexisting resistance, which was attributed to the activation of one or more of the aforementioned evasive resistance mechanisms, not in response to therapy but to the selective pressure of their microenvironment. Thus, it is important to identify markers of resistance and to identify new approaches for targeting angiogenesis.

\section{The Significance and Therapeutic Relevance of ILK1 in the Resistance to Antiangiogenic Therapy}

We used Platelet Factor 4-DLR (PF4- DLR), a peptide derived by inserting DLR mutations into a PF4 47-70 aa fragment from Platelet Factor 4 that exhibits strong antiangiogenesis effects and that reduces angiogenesis and tumor growth in a dose-dependent manner in the U87-MG model [152]. This inhibitor has been widely used in human glioblastoma models, in which it significantly inhibits tumor angiogenesis and growth. However, prolonged treatment with PF4-DLR alone or in combination leads to the development of drug resistance, depending on the dose and the tumors stage at which it is administered [153].

Using a proteomics approach, we identified proteins that were differentially expressed in tumors treated with PF4DLR at two time points: after 10 days of treatment when the tumors are responsive to the antiangiogenic therapy, and after 20 days of treatment when glioblastomas are still responsive to PF4-DLR. However, if treatment is prolonged, glioblastomas start to activate new pathways that might induce drug resistance. The significance of Integrin-linked kinase 1 (ILK1) expression after PF4-DLR treatment was investigated in greater detail. Interestingly, we found that ILK1 expression is downregulated after 10 days of treatment and upregulated after twenty days. This result suggested that ILK1 expression correlates with treatment response, at least in our experimental model. ILK1 is a protein that is involved in intracellular signal transduction of integrins and growth factor receptors. In some tumors, increased ILK1 levels are required for cell growth/survival, cell cycle progression, invasion and migration, and tumor angiogenesis [154]. In glioblastoma, a link between ILK1 and tumor cell invasion has been proposed [155]. Over time, ILK1 increases the expression of VEGF, implying that ILK1 might be a key molecule for a positive signaling loop that induces angiogenesis and tumor growth. Edwards et al. demonstrated that inhibiting ILK1 with small molecule inhibitors reduces tumor hypoxia, decreases tumor vascular mass and decreases functional vasculature in a mouse model of glioblastoma [156]. The inhibition of ILK1 alone was able to delay but could not completely inhibit tumor growth. We therefore decided to inhibit ILK1 using siRNA in addition to PF4-DLR administration in order to investigate whether this combinatorial approach would further improve therapeutic efficacy in vivo over PF4-DLR treatment alone. Interestingly, treatment with PF4-DLR and an anti-ILK1 siRNA resulted in decreased 
tumor mass and a reduction in the number of tumor vessels. Our findings have important therapeutic implications and suggest that combinatorial strategies that simultaneously inhibit different mechanisms of tumor proliferation and angiogenesis might significantly increase therapeutic efficacy. We also analyzed the ILK1 expression levels in patients with glioblastomas, astrocytomas and oligodendrogliomas and found that high levels of ILK1 expression correlate with poor prognosis. Our data suggest that ILK1 could represent a novel specific pharmacological target to be inhibited alone or in combination with antiangiogenic therapies for gliomas [157].

\section{Future Perspectives}

The VEGF family members, angiopoietins, Notch/Delta4 or platelet-derived growth factor are currently the major focus of angiogenesis research. However, many other regulatory molecules, including chemokines, critically modulate vessel growth. The inhibition of IL- 6 and VEGF results in the inhibition of U-87-derived experimental glioma growth on chick CAM (chorioallantoic membrane) or in xenografts in the brains of mice [158].

If a tumor depends on the activity of a single kinase, a new approach is to target the overactive kinase using multiple drugs. However, prolonged therapy can again select for mutations that give rise to therapeutic resistance of the tumor $[159,160]$.

An alternative strategy is to target groups of different kinases. This approach has been demonstrated to be effective in animal models and is undergoing clinical testing. At least 21 clinical trials are currently evaluating the combination of a tyrosine kinase inhibitor and an mTOR inhibitor in several different types of cancer.

The specific targeting and delivery to malignant cell populations can be achieved by targeting cell surface receptors that are either uniquely expressed or overexpressed on cancer cells. A variety of ligands have been evaluated for this purpose, alone or affixed to nanoparticles, antibodies and related fragments, other proteins, peptides, or aptamers. On the basis of the discovery that most human tumors express a high density of specific receptors, it has been possible to develop radiolabeled peptides that localize to these tumors and their metastases for therapeutic targeting [161]. For example, NP-Apt (nanoparticle-aptamer) bioconjugates have demonstrated therapeutic efficacy both in vitro and in vivo against cancer cells.

Modular nanotransporters (MNTS) are recombinant multifunctional polypeptides created to exploit a cascade of cellular processes, from the initiation of membrane receptor recognition to the delivery of selective short-range and highly cytotoxic therapeutic agents into the cells. Slastnikova et al. demonstrated that MNT can selectively deliver drugs into the nuclei of tumor cells that express a targeted receptor, thereby improving the specificity of the therapeutic drugs [162].

Aptamers are oligonucleic acid or peptide molecules that can bind to target molecules (nucleic acids, proteins, small molecules, and even cells) expressed on both on membrane surfaces and intracellularly. Aptamers are more advantageous than antibodies because are easy to synthesize and can be conjugated to fluorescent dyes or chemically modified to exhibit low immunogenicity. However, a major limitation in their clinical application is their low bioavailability after administration.

Aptamers have been used both as a tool to find new targets in cancer therapy and as therapeutic agents against tumor angiogenesis [163]. In December 2004, the US FDA approved pegaptanib (Macugen), an anti-VEGF RNA aptamer, for the treatment of all types of neovascular agerelated macular degeneration. Pegaptanib is the first aptamer to be successfully developed as a therapeutic agent for clinical application in humans [164].

\section{Acknowledgment}

This work was supported by an AIRC Foundation (Italian Association for Cancer Research) Grant (2010 IG 10807).

\section{References}

[1] L. Bello, C. Giussani, G. Carrabba, M. Pluderi, F. Costa, and A. Bikfalvi, "Angiogenesis and invasion in gliomas," Cancer treatment and research, vol. 117, pp. 263-284, 2004.

[2] K. H. Plate, G. Breier, H. A. Weich, H. D. Mennel, and W. Risau, "Vascular endothelial growth factor and glioma angiogenesis: coordinate induction of VEGF receptors, distribution of VEGF protein and possible in vivo regulatory mechanisms," International Journal of Cancer, vol. 59, no. 4, pp. 520-529, 1994.

[3] D. G. Duda, T. T. Batchelor, C. G. Willett, and R. K. Jain, "VEGF-targeted Cancer therapy strategies: current progress, hurdles and future prospects," Trends in Molecular Medicine, vol. 13, no. 6, pp. 223-230, 2007.

[4] D. G. Duda, K. S. Cohen, D. T. Scadden, and R. K. Jain, "A protocol for phenotypic detection and enumeration of circulating endothelial cells and circulating progenitor cells in human blood," Nature Protocols, vol. 2, no. 4, pp. 805-810, 2007.

[5] F. Bertolini, Y. Shaked, P. Mancuso, and R. S. Kerbel, "The multifaceted circulating endothelial cell in Cancer: towards marker and target identification," Nature Reviews Cancer, vol. 6, no. 11, pp. 835-845, 2006.

[6] S. L. Holbeck, "Update on NCI in vitro drug screen utilities," European Journal of Cancer, vol. 40, no. 6, pp. 785-793, 2004.

[7] K. D. Paull, R. H. Shoemaker, L. Hodes et al., "Display and analysis of patterns of differential activity of drugs against human tumor cell lines: development of mean graph and COMPARE algorithm," Journal of the National Cancer Institute, vol. 81, no. 14, pp. 1088-1092, 1989.

[8] B. Lambert, L. De Ridder, F. De Vos et al., "Assessment of supra-additive effects of cytotoxic drugs and low dose rate irradiation in an in vitro model for hepatocellular carcinoma," Canadian journal of physiology and pharmacology, vol. 84, no. 10, pp. 1021-1028, 2006.

[9] H. Hirschberg, C. H. Sun, T. Krasieva, and S. J. Madsen, "Effects of ALA-mediated photodynamic therapy on the invasiveness of human glioma cells," Lasers in Surgery and Medicine, vol. 38, no. 10, pp. 939-945, 2006.

[10] J. Kern, M. Steurer, G. Gastl, E. Gunsilius, and G. Untergasser, "Vasohibin inhibits angiogenic sprouting in vitro 
and supports vascular maturation processes in vivo," $B M C$ Cancer, vol. 9, article 1471, p. 284, 2009.

[11] L. A. Kunz-Schughart, J. A. Schroeder, M. Wondrak et al., "Potential of fibroblasts to regulate the formation of threedimensional vessel-like structures from endothelial cells in vitro," American Journal of Physiology, vol. 290, no. 5, pp. C1385-C1398, 2006.

[12] S. Ghosh, M. B. Joshi, D. Ivanov et al., "Use of multicellular tumor spheroids to dissect endothelial cell-tumor cell interactions: a role for T-cadherin in tumor angiogenesis," FEBS Letters, vol. 581, no. 23, pp. 4523-4528, 2007.

[13] K. W. Kross, J. H. Heimdal, C. Olsnes, J. Olofsson, and H. J. Aarstad, "Co-culture of head and neck squamous cell carcinoma spheroids with autologous monocytes predicts prognosis," Scandinavian Journal of Immunology, vol. 67, no. 4, pp. 392-399, 2008.

[14] F. Durupt, D. Koppers-Lalic, B. Balme et al., "The chicken chorioallantoic membrane tumor assay as model for qualitative testing of oncolytic adenoviruses," Cancer Gene Therapy, vol. 19, no. 1, pp. 58-68, 2012.

[15] L. Ko, A. Koestner, and W. Wechsler, "Morphological characterization of nitrosourea-induced glioma cell lines and clones," Acta Neuropathologica, vol. 51, no. 1, pp. 23-31, 1980.

[16] E. A. Sausville and A. M. Burger, "Contributions of human tumor xenografts to antiCancer drug development," Cancer Research, vol. 66, no. 7, pp. 3351-3354, 2006.

[17] G. G. Steel, V. D. Courtenay, and M. J. Peckham, "The response to chemotherapy of a variety of human tumour xenografts," British Journal of Cancer, vol. 47, no. 1, pp. 1-13, 1983.

[18] T. H. Kuo, T. Kubota, M. Watanabe et al., "Site-specific chemosensitivity of human small-cell lung carcinoma growing orthotopically compared to subcutaneously in SCID mice: the importance of orthotopic models to obtain relevant drug evaluation data," AntiCancer Research, vol. 13, no. 3, pp. 627-630, 1993.

[19] R. M. Hoffman, "Orthotopic metastatic mouse models for anticancer drug discovery and evaluation: a bridge to the clinic," Investigational New Drugs, vol. 17, no. 4, pp. 343-359, 1999.

[20] M. Candolfi, J. F. Curtin, W. S. Nichols et al., "Intracranial glioblastoma models in preclinical neuro-oncology: neuropathological characterization and tumor progression," Journal of Neuro-Oncology, vol. 85, no. 2, pp. 133-148, 2007.

[21] S. Inoue et al., "Novel animal glioma models that separately exhibit two different invasive and angiogenic phenotypes of human glioblastomas," World Neurosurg. In press.

[22] M. A. Elmeliegy, A. M. Carcaboso, L. M. L. Chow et al., "Magnetic resonance imaging-guided microdialysis cannula implantation in a spontaneous high-grade glioma murine model," Journal of Pharmaceutical Sciences, vol. 100, no. 10, pp. 4210-4214, 2011.

[23] L. Chow, R. Endersby, X. Zhu et al., "Cooperativity within and among Pten, $\mathrm{p} 53$, and $\mathrm{Rb}$ pathways induces high-grade astrocytoma in adult brain," Cancer Cell, vol. 19, no. 3, pp. 305-316, 2011.

[24] L. M. Shelton, P. Mukherjee, L. C. Huysentruyt, I. Urits, J. A. Rosenberg, and T. N. Seyfried, "A novel pre-clinical in vivo mouse model for malignant brain tumor growth and invasion," Journal of Neuro-Oncology, vol. 99, no. 2, pp. 165176, 2010.
[25] P. J. Dickinson, R. A. LeCouteur, R. J. Higgins et al., "Canine spontaneous glioma: a translational model system for convection-enhanced delivery," Neuro-Oncology, vol. 12, no. 9, pp. 928-940, 2010.

[26] G. L. Heidner, J. N. Kornegay, R. L. Page, R. K. Dodge, and D. E. Thrall, "Analysis of survival in a retrospective study of 86 dogs with brain tumors," Journal of Veterinary Internal Medicine, vol. 5, no. 4, pp. 219-226, 1991.

[27] N. Kobayashi, N. Allen, and N. R. Clendenon, "An improved rat brain-tumor model," Journal of Neurosurgery, vol. 53, no. 6, pp. 808-815, 1980.

[28] J. Holash, P. C. Maisonpierre, D. Compton et al., "Vessel cooption, regression, and growth in tumors mediated by angiopoietins and VEGF," Science, vol. 284, no. 5422, pp. 1994-1998, 1999.

[29] S. Brem, R. Cotran, and J. Folkman, "Tumor angiogenesis: a quantitative method for histologic grading," Journal of the National Cancer Institute, vol. 48, no. 2, pp. 347-356, 1972.

[30] B. Birlik, S. Canda, and E. Ozer, "Tumour vascularity is of prognostic significance in adult, but not paediatric astrocytomas," Neuropathology and Applied Neurobiology, vol. 32, no. 5, pp. 532-538, 2006.

[31] S. P. Leon, R. D. Folkerth, and P. McL. Black, "Microvessel density is a prognostic indicator for patients with astroglial brain tumors," Cancer, vol. 77, no. 2, pp. 362-372, 1996.

[32] A. Tandle, D. G. Blazer, and S. K. Libutti, "Antiangiogenic gene therapy of Cancer: recent developments," Journal of Translational Medicine, vol. 2, article 22, 2004.

[33] K. M. Dameron, O. V. Volpert, M. A. Tainsky, and N. Bouck, "Control of angiogenesis in fibroblasts by p53 regulation of thrombospondin-1," Science, vol. 265, no. 5178, pp. 15821584, 1994.

[34] D. J. Good, P. J. Polverini, F. Rastinejad et al., "A tumor suppressor-dependent inhibitor of angiogenesis is immunologically and functionally indistinguishable from a fragment of thrombospondin," Proceedings of the National Academy of Sciences of the United States of America, vol. 87, no. 17, pp. 6624-6628, 1990.

[35] J. Fang, Y. Shing, D. Wiederschain et al., "Matrix metalloproteinase-2 is required for the switch to the angiogenic phenotype in a tumor model," Proceedings of the National Academy of Sciences of the United States of America, vol. 97, no. 8, pp. 3884-3889, 2000.

[36] S. A. Raithatha, H. Muzik, N. B. Rewcastle, R. N. Johnston, D. R. Edwards, and P. A. Forsyth, "Localization of gelatinaseA and gelatinase-B mRNA and protein in human gliomas," Neuro-Oncology, vol. 2, no. 3, pp. 145-150, 2000.

[37] T. Martens, Y. Laabs, H. S. Günther et al., "Inhibition of glioblastoma growth in a highly invasive nude mouse model can be achieved by targeting epidermal growth factor receptor but not vascular endothelial growth factor receptor2," Clinical Cancer Research, vol. 14, no. 17, pp. 5447-5458, 2008.

[38] D. Hanahan and J. Folkman, "Patterns and emerging mechanisms of the angiogenic switch during tumorigenesis," Cell, vol. 86, no. 3, pp. 353-364, 1996.

[39] Y. Zhang, N. Zhang, B. Dai et al., "FoxM1B transcriptionally regulates vascular endothelial growth factor expression and promotes the angiogenesis and growth of glioma cells," Cancer Research, vol. 68, no. 21, pp. 8733-8742, 2008.

[40] K. Ido, T. Nakagawa, T. Sakuma, H. Takeuchi, K. Sato, and T. Kubota, "Expression of vascular endothelial growth factor-A 
and mRNA stability factor HuR in human astrocytic tumors," Neuropathology, vol. 28, no. 6, pp. 604-611, 2008.

[41] K. Nakamura, K. C. Martin, J. K. Jackson, K. Beppu, C. W. Woo, and C. J. Thiele, "Brain-derived neurotrophic factor activation of TrkB induces vascular endothelial growth factor expression via hypoxia-inducible factor- $1 \alpha$ in neuroblastoma cells," Cancer Research, vol. 66, no. 8, pp. 4249-4255, 2006.

[42] C. Tan, S. Cruet-Hennequart, A. Troussard et al., "Regulation of tumor angiogenesis by integrin-linked kinase (ILK)," Cancer Cell, vol. 5, no. 1, pp. 79-90, 2004.

[43] K. H. Plate, G. Breier, H. A. Weich, and W. Risau, "Vascular endothelial growth factor is a potential tumour angiogenssis factor in human gliomas in vivo," Nature, vol. 359, no. 6398, pp. 845-848, 1992.

[44] M. Kerber, Y. Reiss, A. Wickersheim et al., "Flt-1 signaling in macrophages promotes glioma growth in vivo," Cancer Research, vol. 68, no. 18, pp. 7342-7351, 2008.

[45] E. Y. Lin and J. W. Pollard, "Tumor-associated macrophages press the angiogenic switch in breast Cancer," Cancer Research, vol. 67, no. 11, pp. 5064-5066, 2007.

[46] M. K. Jones, R. M. Itani, H. Wang et al., "Activation of VEGF and Ras genes in gastric mucosa during angiogenic response to ethanol injury," American Journal of Physiology, vol. 276, part 1, no. 6, pp. G1345-G1355, 1999.

[47] T. Takahashi and M. Shibuya, "The $230 \mathrm{kDa}$ mature form of KDR/Flk-1 (VEGF receptor-2) activates the PLC- $\gamma$ pathway and partially induces mitotic signals in NIH3T3 fibroblasts," Oncogene, vol. 14, no. 17, pp. 2079-2089, 1997.

[48] B. K. Lal, S. Varma, P. J. Pappas, R. W. Hobson, and W. N. Durán, "VEGF increases permeability of the endothelial cell monolayer by activation of PKB/akt, endothelial nitric-oxide synthase, and MAP kinase pathways," Microvascular Research, vol. 62, no. 3, pp. 252-262, 2001.

[49] S. Esser, K. Wolburg, H. Wolburg, G. Breier, T. Kurzchalia, and W. Risau, "Vascular endothelial growth factor induces endothelial fenestrations in vitro," Journal of Cell Biology, vol. 140, no. 4, pp. 947-959, 1998.

[50] C. G. Kevil, N. Ohno, D. C. Gute et al., "Role of cadherin internalization in hydrogen peroxide-mediated endothelial permeability," Free Radical Biology and Medicine, vol. 24, no. 6, pp. 1015-1022, 1998.

[51] B. Li, C. M. Chang, M. Yuan, W. G. McKenna, and H. K. G. Shu, "Resistance to small molecule inhibitors of epidermal growth factor receptor in malignant gliomas," Cancer Research, vol. 63, no. 21, pp. 7443-7450, 2003.

[52] M. Takahashi, A. Matsui, M. Inao, S. Mochida, and K. Fujiwara, "ERK/MAPK-dependent PI3K/Akt phosphorylation through VEGFR-1 after VEGF stimulation in activated hepatic stellate cells," Hepatology Research, vol. 26, no. 3, pp. 232-236, 2003.

[53] R. C. Castellino and D. L. Durden, "Mechanisms of disease: the PI3K-Akt-PTEN signaling node-an intercept point for the control of angiogenesis in brain tumors," Nature Clinical Practice Neurology, vol. 3, no. 12, pp. 682-693, 2007.

[54] S. K. Hobbs, W. L. Monsky, F. Yuan et al., "Regulation of transport pathways in tumor vessels: role of tumor type and microenvironment," Proceedings of the National Academy of Sciences of the United States of America, vol. 95, no. 8, pp. 4607-4612, 1998.

[55] W. L. Monsky, D. Fukumura, T. Gohongi et al., "Augmentation of transvascular transport of macromolecules and nanoparticles in tumors using vascular endothelial growth factor," Cancer Research, vol. 59, no. 16, pp. 4129-4135, 1999.
[56] E. Bullitt, D. Zeng, G. Gerig et al., "Vessel tortuosity and brain tumor malignancy: a blinded study," Academic Radiology, vol. 12, no. 10, pp. 1232-1240, 2005.

[57] D. Zagzag, A. Hooper, D. R. Friedlander et al., "In situ expression of angiopoietins in astrocytomas identifies angiopoietin-2 as an early marker of tumor angiogenesis," Experimental Neurology, vol. 159, no. 2, pp. 391-400, 1999.

[58] N. Ferrara, H. P. Gerber, and J. LeCouter, "The biology of VEGF and its receptors," Nature Medicine, vol. 9, no. 6, pp. 669-676, 2003.

[59] K. J. Kim, B. Li, J. Winer et al., "Inhibition of vascular endothelial growth factor-induced angiogenesis suppresses tumour growth in vivo," Nature, vol. 362, no. 6423, pp. 841844, 1993.

[60] H. Hurwitz, L. Fehrenbacher, W. Novotny et al., "Bevacizumab plus irinotecan, fluorouracil, and leucovorin for metastatic colorectal Cancer," The New England Journal of Medicine, vol. 350, no. 23, pp. 2335-2342, 2004.

[61] M. C. Chamberlain, "Bevacizumab for the treatment of recurrent glioblastoma," Clinical Medicine Insights, vol. 5, pp. 117-129, 2011.

[62] D. Shweiki, A. Itin, D. Soffer, and E. Keshet, "Vascular endothelial growth factor induced by hypoxia may mediate hypoxia-initiated angiogenesis," Nature, vol. 359, no. 6398, pp. 843-845, 1992.

[63] E. J. Bernhard, "Interventions that induce modifications in the tumor microenvironment," Cancer/Radiotherapie, vol. 15, no. 5, pp. 376-382, 2011.

[64] M. Relf, S. Lejeune, P. A. E. Scott et al., "Expression of the angiogenic factors vascular endothelial cell growth factor, acidic and basic fibroblast growth factor, tumor growth factor $\beta-1$, platelet-derived endothelial cell growth factor, placenta growth factor, and pleiotrophin in human primary breast Cancer and its relation to angiogenesis," Cancer Research, vol. 57, no. 5, pp. 963-969, 1997.

[65] R. Kerbel and J. Folkman, "Clinical translation of angiogenesis inhibitors," Nature Reviews Cancer, vol. 2, no. 10, pp. 727739, 2002.

[66] A. Abdollahi, K. E. Lipson, A. Sckell et al., "Combined therapy with direct and indirect angiogenesis inhibition results in enhanced antiangiogenic and antitumor effects," Cancer Research, vol. 63, no. 24, pp. 8890-8898, 2003.

[67] J. Wang, Y. Sun, Y. Liu et al., "Results of randomized, multicenter, double-blind phase III trial of rh-endostatin (YH-16) in treatment of advanced non-small cell lung cancer patients," Chinese Journal of Lung Cancer, vol. 8, no. 4, pp. 283-290, 2005.

[68] M. R. Gilbert, J. Kuhn, K. R. Lamborn et al., "Cilengitide in patients with recurrent glioblastoma: the results of NABTC 03-02, a phase II trial with measures of treatment delivery," Journal of Neuro-Oncology, pp. 1-7, 2011.

[69] R. Stupp, M. E. Hegi, B. Neyns et al., "Phase I/IIa study of cilengitide and temozolomide with concomitant radiotherapy followed by cilengitide and temozolomide maintenance therapy in patients with newly diagnosed glioblastoma," Journal of Clinical Oncology, vol. 28, no. 16, pp. 2712-2718, 2010.

[70] C. Delbaldo, E. Raymond, K. Vera et al., "Phase I and pharmacokinetic study of etaracizumab (Abegrin), a humanized monoclonal antibody against $\alpha \mathrm{v} \beta 3$ integrin receptor, in patients with advanced solid tumors," Investigational New Drugs, vol. 26, no. 1, pp. 35-43, 2008.

[71] P. Hersey, J. Sosman, S. O’Day et al., "A randomized phase 2 study of etaracizumab, a monoclonal antibody against 
integrin $\alpha \mathrm{v} \beta 3, \pm$ dacarbazine in patients with stage IV metastatic melanoma," Cancer, vol. 116, no. 6, pp. 15261534, 2010.

[72] K. M. Bell-Mcguinn, C. M. Matthews, S. N. Ho et al., "A phase II, single-arm study of the anti- $\alpha 5 \beta 1$ integrin antibody volociximab as monotherapy in patients with platinumresistant advanced epithelial ovarian or primary peritoneal Cancer," Gynecologic Oncology, vol. 121, no. 2, pp. 273-279, 2011.

[73] V. A. Levin, S. Phuphanich, W. K. A. Yung et al., "Randomized, double-blind, placebo-controlled trial of marimastat in glioblastoma multiforme patients following surgery and irradiation," Journal of Neuro-Oncology, vol. 78, no. 3, pp. 295-302, 2006.

[74] F. A. Shepherd, G. Giaccone, L. Seymour et al., "Prospective, randomized, double-blind, placebo-controlled trial of marimastat after response to first-line chemotherapy in patients with small-cell lung Cancer: a trial of the National Cancer Institute of Canada-Clinical Trials Group and the European Organization for Research and Treatment of Cancer," Journal of Clinical Oncology, vol. 20, no. 22, pp. 4434-4439, 2002.

[75] D. A. Reardon, J. J. Vredenburgh, A. Coan et al., "Phase i study of sunitinib and irinotecan for patients with recurrent malignant glioma," Journal of Neuro-Oncology, vol. 105, no. 3, pp. 621-627, 2011.

[76] L. B. Nabors, J. G. Supko, M. Rosenfeld et al., "Phase I trial of sorafenib in patients with recurrent or progressive malignant glioma," Neuro-Oncology, vol. 13, no. 12, pp. 1324-1330, 2011.

[77] L. L. Garland, K. Chansky, A. J. Wozniak et al., "Phase II study of cediranib in patients with Malignant pleural mesothelioma: SWOG S0509," Journal of Thoracic Oncology, vol. 6, no. 11, pp. 1938-1945, 2011.

[78] S. R. Alberts, T. R. Fitch, G. P. Kim et al., "Cediranib (AZD2171) in patients with advanced hepatocellular carcinoma: a phase II north central Cancer treatment group clinical trial," American Journal of Clinical Oncology, 2011.

[79] T. T. Batchelor, D. G. Duda, E. Di Tomaso et al., "Phase II study of cediranib, an oral pan-vascular endothelial growth factor receptor tyrosine kinase inhibitor, in patients with recurrent glioblastoma," Journal of Clinical Oncology, vol. 28, no. 17, pp. 2817-2823, 2010.

[80] B. Neyns, J. Sadones, C. Chaskis et al., "Phase II study of sunitinib malate in patients with recurrent high-grade glioma," Journal of Neuro-Oncology, vol. 103, no. 3, pp. 491501, 2011.

[81] D. A. Reardon, G. Dresemann, S. Taillibert et al., "Multicentre phase II studies evaluating imatinib plus hydroxyurea in patients with progressive glioblastoma," British Journal of Cancer, vol. 101, no. 12, pp. 1995-2004, 2009.

[82] E. Razis, P. Selviaridis, S. Labropoulos et al., "Phase II study of neoadjuvant imatinib in glioblastoma: evaluation of clinical and molecular effects of the treatment," Clinical Cancer Research, vol. 15, no. 19, pp. 6258-6266, 2009.

[83] G. Dresemann, M. Weller, M. A. Rosenthal et al., "Imatinib in combination with hydroxyurea versus hydroxyurea alone as oral therapy in patients with progressive pretreated glioblastoma resistant to standard dose temozolomide," Journal of Neuro-Oncology, vol. 96, no. 3, pp. 393-402, 2010.

[84] J. J. Vredenburgh, A. Desjardins, J. E. Herndon et al., "Phase II trial of bevacizumab and irinotecan in recurrent malignant glioma," Clinical Cancer Research, vol. 13, no. 4, pp. 1253 1259, 2007.
[85] A. D. Norden, J. Drappatz, A. Muzikansky et al., "An exploratory survival analysis of anti-angiogenic therapy for recurrent malignant glioma," Journal of Neuro-Oncology, vol. 92, no. 2, pp. 149-155, 2009.

[86] T. Xu, J. Chen, Y. Lu, and J. E. A. Wolff, "Effects of bevacizumab plus irinotecan on response and survival in patients with recurrent malignant glioma: a systematic review and survival-gain analysis," BMC Cancer, vol. 10, article 252, 2010.

[87] O. Keunen, M. Johansson, A. Oudin et al., "Anti-VEGF treatment reduces blood supply and increases tumor cell invasion in glioblastoma," Proceedings of the National Academy of Sciences of the United States of America, vol. 108, no. 9, pp. 3749-3754, 2011.

[88] A. K. Lucio-Eterovic, Y. Piao, and J. F. De Groot, "Mediators of glioblastoma resistance and invasion during antivascular endothelial growth factor therapy," Clinical Cancer Research, vol. 15, no. 14, pp. 4589-4599, 2009.

[89] V. Lorgis et al., "Relation between bevacizumab dose intensity and high-grade glioma survival: a retrospective study in two large cohorts," Journal of Neurooncol, vol. 107, no. 2, pp. 351-358, 2012.

[90] S. M. Sweeney, G. DiLullo, S. J. Slater et al., "Angiogenesis in collagen I requires $\alpha 2 \beta 1$ ligation of a GFP $*$ GER sequence and possibly p38 MAPK activation and focal adhesion disassembly," The Journal of Biological Chemistry, vol. 278, no. 33, pp. 30516-30524, 2003.

[91] D. R. Senger, C. A. Perruzzi, M. Streit, V. E. Koteliansky, A. R. De Fougerolles, and M. Detmar, "The $\alpha 1 \beta 1$ and $\alpha 2 \beta 1$ integrins provide critical support for vascular endothelial growth factor signaling, endothelial cell migration, and tumor angiogenesis," American Journal of Pathology, vol. 160, no. 1, pp. 195-204, 2002.

[92] P. C. Brooks, R. A. F. Clark, and D. A. Cheresh, "Requirement of vascular integrin $\alpha(\mathrm{v}) \beta 3$ for angiogenesis," Science, vol. 264, no. 5158, pp. 569-571, 1994.

[93] M. Friedlander, P. C. Brooks, R. W. Shaffer, C. M. Kincaid, J. A. Varner, and D. A. Cheresh, "Definition of two angiogenic pathways by distinct $\alpha \mathrm{v}$ integrins," Science, vol. 270, no. 5241, pp. 1500-1502, 1995.

[94] C. J. Drake, D. A. Cheresh, and C. D. Little, "An antagonist of integrin $\alpha(\mathrm{v}) \beta 3$ prevents maturation of blood vessels during embryonic neovascularization," Journal of Cell Science, vol. 108, no. 7, pp. 2655-2661, 1995.

[95] Y. Fu, M. L. Ponce, M. Thill, P. Yuan, S. W. Nam, and K. G. Csaky, "Angiogenesis inhibition and choroidal neovascularization suppression by sustained delivery of an integrin antagonist, EMD478761," Investigative Ophthalmology and Visual Science, vol. 48, no. 11, pp. 5184-5190, 2007.

[96] D. A. Reardon, K. L. Fink, T. Mikkelsen et al., "Randomized phase II study of cilengitide, an integrin-targeting arginineglycine-aspartic acid peptide, in recurrent glioblastoma multiforme," Journal of Clinical Oncology, vol. 26, no. 34, pp. 5610-5617, 2008.

[97] J. B. Vermorken, J. Guigay, R. Mesia et al., "Phase I/II trial of cilengitide with cetuximab, cisplatin and 5-fluorouracil in recurrent and/or metastatic squamous cell Cancer of the head and neck: findings of the phase i part," British Journal of Cancer, vol. 104, no. 11, pp. 1691-1696, 2011.

[98] D. A. Reardon, B. Neyns, M. Weller, J. C. Tonn, L. B. Nabors, and R. Stupp, "Cilengitide: an RGD pentapeptide $\alpha \nu \beta 3$ and 
$\alpha v \beta 5$ integrin inhibitor in development for glioblastoma and other malignancies," Future Oncology, vol. 7, no. 3, pp. 339354, 2011.

[99] W. Cai, Y. Wu, K. Chen, Q. Cao, D. A. Tice, and X. Chen, "In vitro and in vivo characterization of $64 \mathrm{Cu}$-labeled Abegrin, a humanized monoclonal antibody against integrin $\alpha \mathrm{v} \beta 3$," Cancer Research, vol. 66, no. 19, pp. 9673-9681, 2006.

[100] A. D. Ricart, A. W. Tolcher, G. Liu et al., "Volociximab, a chimeric monoclonal antibody that specifically binds $\alpha 5 \beta 1$ integrin: a phase 1, pharmacokinetic, and biological correlative study," Clinical Cancer Research, vol. 14, no. 23, pp. 7924-7929, 2008.

[101] M. D. Groves, V. K. Puduvalli, K. R. Hess et al., "Phase II trial of temozolomide plus the matrix metalloproteinase inhibitor, marimastat, in recurrent and progressive glioblastoma multiforme," Journal of Clinical Oncology, vol. 20, no. 5, pp. 13831388, 2002.

[102] M. L. H. Wong, A. Prawira, A. H. Kaye, and C. M. Hovens, "Tumour angiogenesis: its mechanism and therapeutic implications in malignant gliomas," Journal of Clinical Neuroscience, vol. 16, no. 9, pp. 1119-1130, 2009.

[103] M. L. Maitland, K. E. Kasza, T. Karrison et al., "Ambulatory monitoring detects sorafenib-induced blood pressure elevations on the first day of treatment," Clinical Cancer Research, vol. 15, no. 19, pp. 6250-6257, 2009.

[104] W. Fiedler, R. Mesters, M. Heuser et al., "An open-label, Phase I study of cediranib (RECENTIN) in patients with acute myeloid Leukemia," Leukemia Research, vol. 34, no. 2, pp. 196-202, 2010.

[105] R. J. Motzer, T. E. Hutson, P. Tomczak et al., "Sunitinib versus interferon alfa in metastatic renal-cell carcinoma," The New England Journal of Medicine, vol. 356, no. 2, pp. 115-124, 2007.

[106] E. Raymond, L. Dahan, J.-L. Raoul et al., "Sunitinib malate for the treatment of pancreatic neuroendocrine tumors," The New England Journal of Medicine, vol. 364, no. 6, pp. 501-513, 2011.

[107] G. D. Demetri, A. T. van Oosterom, C. R. Garrett et al., "Efficacy and safety of sunitinib in patients with advanced gastrointestinal stromal tumour after failure of imatinib: a randomised controlled trial," The Lancet, vol. 368, no. 9544, pp. 1329-1338, 2006.

[108] S. Matsumoto, S. Batra, K. Saito et al., "Antiangiogenic agent sunitinib transiently increases tumor oxygenation and suppresses cycling hypoxia," Cancer Research, vol. 71, no. 20, pp. 6350-6359, 2011.

[109] E. Ranza, G. Mazzini, A. Facoetti, and R. Nano, "Invitro effects of the tyrosine kinase inhibitor imatinib on glioblastoma cell proliferation," Journal of Neuro-Oncology, vol. 96, no. 3, pp. 349-357, 2010.

[110] P. Y. Wen, W. K. A. Yung, K. R. Lamborn et al., "Phase I/II study of imatinib mesylate for recurrent malignant gliomas: North American brain tumor consortium study 99-08," Clinical Cancer Research, vol. 12, no. 16, pp. 4899-4907, 2006.

[111] Y. Jin, J.-P. Li, L.-Y. Tang et al., "Protein expression and significance of VEGF, EGFR and MMP-9 in non-small cell lung carcinomas," Asian Pacific Journal of Cancer Prevention, vol. 12, no. 6, pp. 1473-1476, 2011.

[112] A. Kamat, S. Rajoria, A. George et al., "Estrogen-mediated angiogenesis in thyroid tumor microenvironment is mediated through VEGF signaling pathways," Archives of Otolaryngology, vol. 137, no. 11, pp. 1146-1153, 2011.
[113] L. B. Saltz, H. J. Lenz, H. L. Kindler et al., "Randomized phase II trial of cetuximab, bevacizumab, and irinotecan compared with cetuximab and bevacizumab alone in irinotecanrefractory colorectal Cancer: the BOND-2 study," Journal of Clinical Oncology, vol. 25, no. 29, pp. 4557-4561, 2007.

[114] H. L. Kindler, D. Niedzwiecki, D. Hollis et al., "Gemcitabine plus bevacizumab compared with gemcitabine plus placebo in patients with advanced pancreatic Cancer: phase III trial of the Cancer and Leukemia group B (CALGB 80303)," Journal of Clinical Oncology, vol. 28, no. 22, pp. 3617-3622, 2010.

[115] O. Casanovas, D. J. Hicklin, G. Bergers, and D. Hanahan, "Drug resistance by evasion of antiangiogenic targeting of VEGF signaling in late-stage pancreatic islet tumors," Cancer Cell, vol. 8, no. 4, pp. 299-309, 2005.

[116] T. Kamba and D. M. McDonald, "Mechanisms of adverse effects of anti-VEGF therapy for Cancer," British Journal of Cancer, vol. 96, no. 12, pp. 1788-1795, 2007.

[117] S. Kourembanas, R. L. Hannan, and D. V. Faller, "Oxygen tension regulates the expression of the platelet-derived growth factor-B chain gene in human endothelial cells," Journal of Clinical Investigation, vol. 86, no. 2, pp. 670-674, 1990.

[118] D. V. Faller, "Endothelial cell responses to hypoxic stress," Clinical and Experimental Pharmacology and Physiology, vol. 26, no. 1, pp. 74-84, 1999.

[119] J. Huang, S. Z. Softer, E. S. Kim et al., "Vascular remodeling marks tumors that recur during chronic suppression of angiogenesis," Molecular Cancer Research, vol. 2, no. 1, pp. 36-42, 2004.

[120] J. L. Rubenstein, J. Kim, T. Ozawa et al., "Anti-VEGF antibody treatment of glioblastoma prolongs survival but results in increased vascular cooption," Neoplasia, vol. 2, no. 4, pp. 306314, 2000.

[121] J. Glade Bender, E. M. Cooney, J. J. Kandel, and D. J. Yamashiro, "Vascular remodeling and clinical resistance to antiangiogenic Cancer therapy," Drug Resistance Updates, vol. 7, no. 4-5, pp. 289-300, 2004.

[122] L. Hiatky, C. Tsionou, P. Hahnfeldt, and C. N. Coleman, "Mammary fibroblasts may influence breast tumor angiogenesis via hypoxia-induced vascular endothelial growth factor up-regulation and protein expression," Cancer Research, vol. 54, no. 23, pp. 6083-6086, 1994.

[123] M. B. Ruzinova, R. A. Schoer, W. Gerald et al., "Effect of angiogenesis inhibition by Id loss and the contribution of bone-marrow-derived endothelial cells in spontaneous murine tumors," Cancer Cell, vol. 4, no. 4, pp. 277-289, 2003.

[124] A. S. Bailey, H. Willenbring, S. Jiang et al., "Myeloid lineage progenitors give rise to vascular endothelium," Proceedings of the National Academy of Sciences of the United States of America, vol. 103, no. 35, pp. 13156-13161, 2006.

[125] F. Shojaei, X. Wu, A. K. Malik et al., "Tumor refractoriness to anti-VEGF treatment is mediated by $\mathrm{CD} 11 \mathrm{~b}^{+} \mathrm{Gr} 1^{+}$myeloid cells," Nature Biotechnology, vol. 25, no. 8, pp. 911-920, 2007.

[126] R. D. Leek, C. E. Lewis, R. Whitehouse, M. Greenall, J. Clarke, and A. L. Harris, "Association of macrophage infiltration with angiogenesis and prognosis in invasive breast carcinoma," Cancer Research, vol. 56, no. 20, pp. 46254629, 1996.

[127] C. E. Lewis and J. W. Pollard, "Distinct role of macrophages in different tumor microenvironments," Cancer Research, vol. 66, no. 2, pp. 605-612, 2006. 
[128] E. Y. Lin, A. V. Nguyen, R. G. Russell, and J. W. Pollard, "Colony-stimulating factor 1 promotes progression of mammary tumors to malignancy," Journal of Experimental Medicine, vol. 193, no. 6, pp. 727-739, 2001.

[129] L. Bingle, N. J. Brown, and C. E. Lewis, "The role of tumourassociated macrophages in tumour progression: implications for new antiCancer therapies," Journal of Pathology, vol. 196, no. 3, pp. 254-265, 2002.

[130] M. Platten, A. Kretz, U. Naumann et al., "Monocyte chemoattractant protein-1 increases microglial infiltration and aggressiveness of gliomas," Annals of Neurology, vol. 54, no. 3, pp. 388-392, 2003.

[131] M. M. Mueller and N. E. Fusenig, "Constitutive expression of G-CSF and GM-CSF in human skin carcinoma cells with functional consequence for tumor progression," International Journal of Cancer, vol. 83, no. 6, pp. 780-789, 1999.

[132] T. W. Briers, C. Desmaretz, and E. Vanmechelen, "Generation and characterization of mouse microglial cell lines," Journal of Neuroimmunology, vol. 52, no. 2, pp. 153-164, 1994.

[133] J. V. Lafuente, B. Adán, K. Alkiza, J. M. Garibi, M. Rossi, and F. F. Cruz-Sánchez, "Expression of vascular endothelial growth factor (VEGF) and platelet-derived growth factor receptor- $\beta$ (PDGFR- $\beta$ ) in human gliomas," Journal of Molecular Neuroscience, vol. 13, no. 1-2, pp. 177-185, 1999.

[134] L. Zhang, T. Himi, and S. Murota, "Induction of hepatocyte growth factor (HGF) in rat microglial cells by prostaglandin E(2)," Journal of Neuroscience Research, vol. 62, no. 3, pp. 389-395, 2000.

[135] P. Kunkel, S. Müller, P. Schirmacher et al., "Expression and localization of scatter factor/hepatocyte growth factor in human astrocytomas," Neuro-Oncology, vol. 3, no. 2, pp. 82$88,2001$.

[136] C. Hao, I. F. Parney, W. H. Roa, J. Turner, K. C. Petruk, and D. A. Ramsay, "Cytokine and cytokine receptor mRNA expression in human glioblastomas: evidence of Th1, Th2 and Th3 cytokine dysregulation," Acta Neuropathologica, vol. 103, no. 2, pp. 171-178, 2002.

[137] H. Galarneau, J. Villeneuve, G. Gowing, J. P. Julien, and L. Vallières, "Increased glioma growth in mice depleted of macrophages," Cancer Research, vol. 67, no. 18, pp. 8874$8881,2007$.

[138] A. Ghosh and S. Chaudhuri, "Microglial action in glioma: a boon turns bane," Immunology Letters, vol. 131, no. 1, pp. 39, 2010.

[139] A. Persson and E. Englund, "The glioma cell edge-winning by engulfing the enemy?" Medical Hypotheses, vol. 73, no. 3, pp. 336-337, 2009.

[140] T. N. Seyfried, M. A. Kiebish, J. Marsh, L. M. Shelton, L. C. Huysentruyt, and P. Mukherjee, "Metabolic management of brain Cancer," Biochimica et Biophysica Acta, vol. 1807, no. 6, pp. 577-594, 2011.

[141] M. Rachkovsky, S. Sodi, A. Chakraborty et al., "Melanoma x macrophage hybrids with enhanced metastatic potential," Clinical and Experimental Metastasis, vol. 16, no. 4, pp. 299312, 1998.

[142] J. M. Pawelek and A. K. Chakraborty, "Fusion of tumour cells with bone marrow-derived cells: a unifying explanation for metastasis," Nature Reviews Cancer, vol. 8, no. 5, pp. 377-386, 2008.

[143] T. Strojnik, R. Kavalar, and T. T. Lah, "Experimental model and immunohistochemical analyses of U87 human glioblastoma cell xenografts in immunosuppressed rat brains," AntiCancer Research, vol. 26, no. 4 B, pp. 2887-2900, 2006.
[144] I. Shabo, H. Olsson, X. F. Sun, and J. Svanvik, "Expression of the macrophage antigen CD163 in rectal Cancer cells is associated with early local recurrence and reduced survival time," International Journal of Cancer, vol. 125, no. 8, pp. 1826-1831, 2009.

[145] T. Browder, C. E. Butterfield, B. M. Kräling et al., "Antiangiogenic scheduling of chemotherapy improves efficacy against experimental drug-resistant Cancer," Cancer Research, vol. 60, no. 7, pp. 1878-1886, 2000.

[146] M. Kioi, H. Vogel, G. Schultz, R. M. Hoffman, G. R. Harsh, and J. M. Brown, "Inhibition of vasculogenesis, but not angiogenesis, prevents the recurrence of glioblastoma after irradiation in mice," Journal of Clinical Investigation, vol. 120, no. 3, pp. 694-705, 2010.

[147] M. Frontczak-Baniewicz, D. Czajkowska, J. Andrychowski, and M. Walski, "The immature endothelial cell in human glioma. Ultrastructural features of blood capillary vessels," Folia Neuropathologica, vol. 46, no. 1, pp. 49-56, 2008.

[148] M. W. Kieran, C. D. Turner, J. B. Rubin et al., "A feasibility trial of antiangiogenic (metronomic) chemotherapy in pediatric patients with recurrent or progressive Cancer," Journal of Pediatric Hematology/Oncology, vol. 27, no. 11, pp. 573581, 2005.

[149] Y. Soda, T. Marumoto, D. Friedmann-Morvinski et al., "Transdifferentiation of glioblastoma cells into vascular endothelial cells," Proceedings of the National Academy of Sciences of the United States of America, vol. 108, no. 11, pp. 4274-4280, 2011.

[150] N. T. Fernando, M. Koch, C. Rothrock et al., “Tumor escape from endogenous, extracellular matrix-associated angiogenesis inhibitors by up-regulation of multiple proangiogenic factors," Clinical Cancer Research, vol. 14, no. 5, pp. 15291539, 2008.

[151] T. T. Batchelor, A. G. Sorensen, E. di Tomaso et al., "AZD2171, a pan-VEGF receptor tyrosine kinase inhibitor, normalizes tumor vasculature and alleviates edema in glioblastoma patients," Cancer Cell, vol. 11, no. 1, pp. 83-95, 2007.

[152] M. Hagedorn, L. Zilberberg, J. Wilting et al., "Domain swapping in a $\mathrm{COOH}$-terminal fragment of platelet factor 4 generates potent angiogenesis inhibitors," Cancer Research, vol. 62 , no. 23 , pp. 6884-6890, 2002.

[153] L. Bello, V. Lucini, F. Costa et al., "Combinatorial administration of molecules that simultaneously inhibit angiogenesis and invasion leads to increased therapeutic efficacy in mouse models of malignant glioma," Clinical Cancer Research, vol. 10, no. 13, pp. 4527-4537, 2004.

[154] D. L. Dai, N. Makretsov, E. I. Campos et al., "Increased expression of integrin-linked kinase is correlated with melanoma progression and poor patient survival," Clinical Cancer Research, vol. 9, no. 12, pp. 4409-4414, 2003.

[155] A. A. Troussard, P. Costello, T. N. Yoganathan, S. Kumagai, C. D. Roskelley, and S. Dedhar, "The integrin linked kinase (ILK) induces an invasive phenotype via AP-1 transcription factor-dependent upregulation of matrix metalloproteinase 9 (MMP-9)," Oncogene, vol. 19, no. 48, pp. 5444-5452, 2000.

[156] L. A. Edwards, J. Woo, L. A. Huxham et al., "Suppression of VEGF secretion and changes in glioblastoma multiforme microenvironment by inhibition of Integrin-linked kinase (ILK)," Molecular Cancer Therapeutics, vol. 7, no. 1, pp. 5970, 2008.

[157] C. Verpelli, G. Bertani, V. Cea et al., "Anti-angiogenic therapy induces integrin-linked kinase 1 up-regulation in a mouse 
model of glioblastoma," PLoS ONE, vol. 5, no. 10, Article ID e13710, 2010.

[158] A. Saidi, M. Hagedorn, N. Allain et al., "Combined targeting of interleukin-6 and vascular endothelial growth factor potently inhibits glioma growth and invasiveness," International Journal of Cancer, vol. 125, no. 5, pp. 10541064, 2009.

[159] A. Quintas-Cardama, H. Kantarjian, D. Jones et al., "Dasatinib (BMS-354825) is active in Philadelphia chromosomepositive chronic myelogenous Leukemia after imatinib and nilotinib (AMN107) therapy failure," Blood, vol. 109, no. 2, pp. 497-499, 2007.

[160] H. Kantarjian, F. Giles, L. Wunderle et al., "Nilotinib in imatinib-resistant CML and Philadelphia chromosomepositive ALL," The New England Journal of Medicine, vol. 354, no. 24, pp. 2542-2551, 2006.

[161] J. C. Reubi and B. Waser, "Unexpected high incidence of cholecystokinin-B/gastrin receptors in human medullary thyroid carcinomas," International Journal of Cancer, vol. 67, no. 5, pp. 644-647, 1996.

[162] T. A. Slastnikova, A. A. Rosenkranz, P. V. Gulak et al., "Modular nanotransporters: a multipurpose in vivo working platform for targeted drug delivery," International Journal of Nanomedicine, vol. 7, pp. 467-482, 2012.

[163] J. R. Kanwar, G. Mahidhara, and R. K. Kanwar, "Antiangiogenic therapy using nanotechnological-based delivery system," Drug Discovery Today, vol. 16, no. 5-6, pp. 188-202, 2011.

[164] E. W. M. Ng, D. T. Shima, P. Calias, E. T. Cunningham, D. R. Guyer, and A. P. Adamis, "Pegaptanib, a targeted anti-VEGF aptamer for ocular vascular disease," Nature Reviews Drug Discovery, vol. 5, no. 2, pp. 123-132, 2006. 

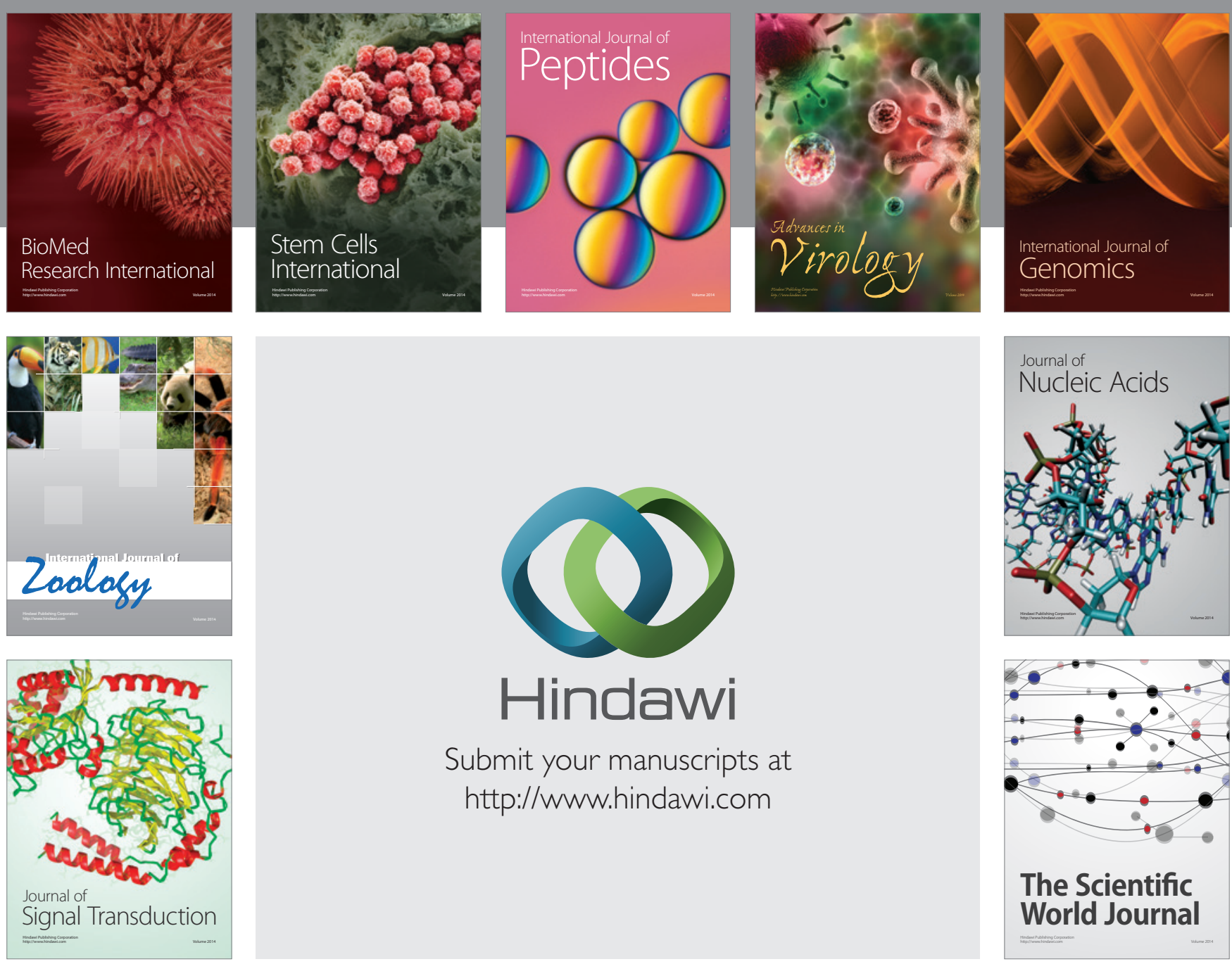

Submit your manuscripts at

http://www.hindawi.com
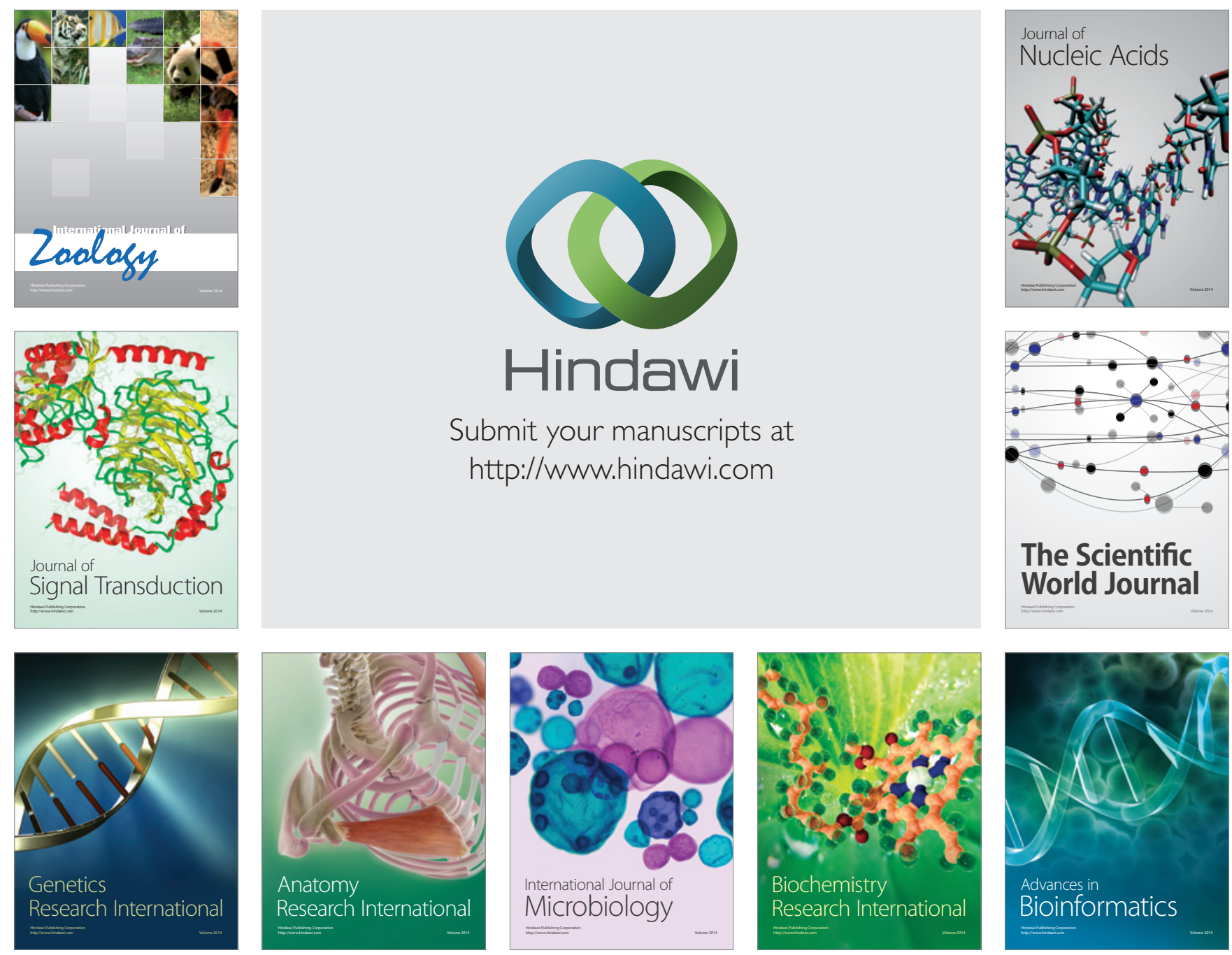

The Scientific World Journal
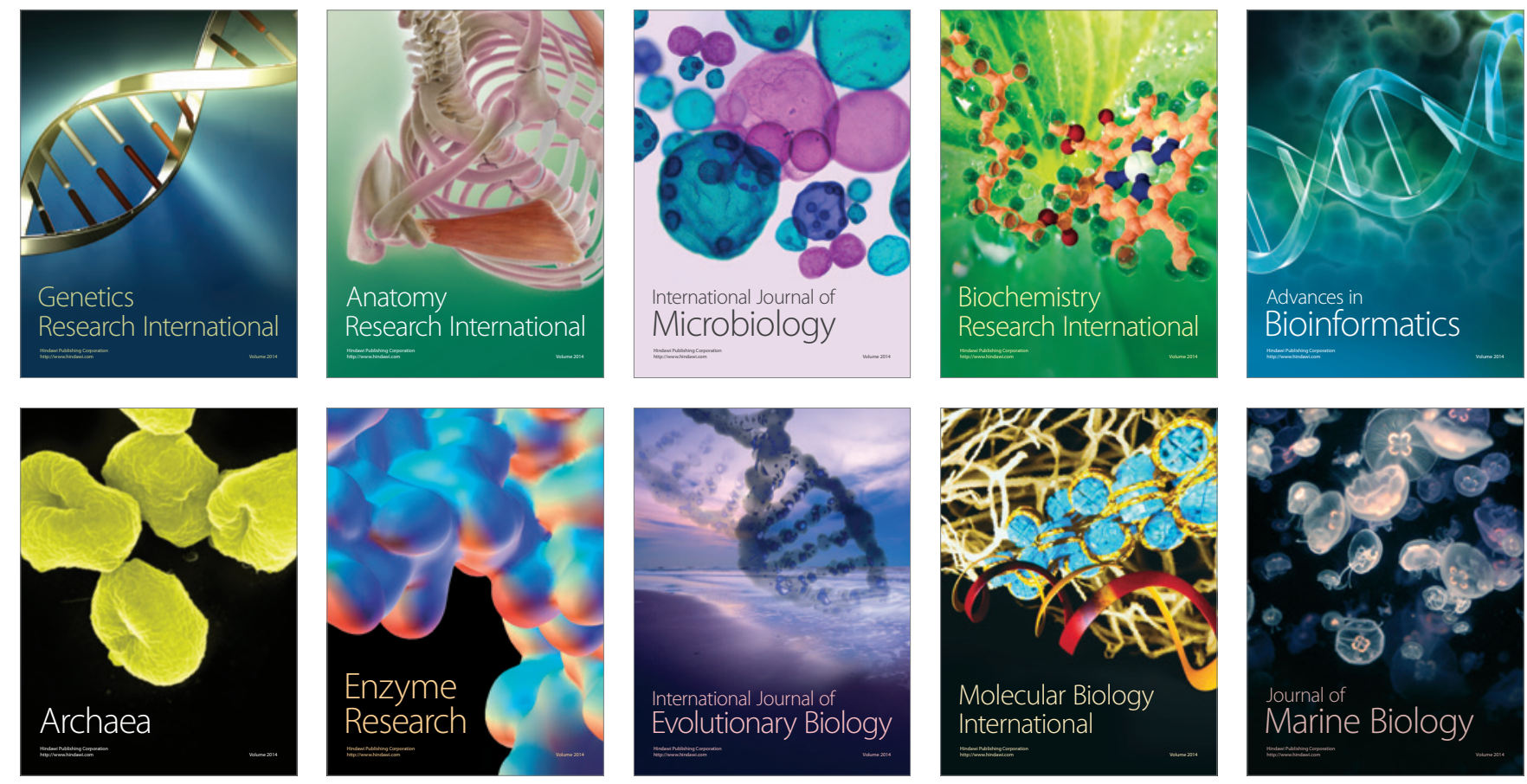